\title{
Paradigma da confissão e arqueologia do si em Nietzsche
}

\author{
Gianfranco Ferraro"
}

\begin{abstract}
Resumo: A experiência da subjetividade moderna vive no fim do século XIX uma deslocação de questões que passam e se manifestam por formas inéditas de escrita. Na recuperação do gênero autobiográfico o Nietzsche de "Ecce homo" está consciente que só uma nova forma do diálogo da consciência consigo mesma pode, assim como aconteceu pelas "Confissões" de Santo Agostinho e pelas "Meditações" de Descartes, fixar a imagem deste novo "eu".
\end{abstract}

Palavras-chave: Ecce homo - confissão - Foucault - forma de vida

No fim do século XIX, a experiência da subjetividade moderna passa pela deslocação duma multiplicidade de forças, psicológicas, sociais, politicas, que não reconhecem os limites que antes reconheciam, e que podem agora manifestar-se em formas inéditas. $\mathrm{O}$ que acontece é o aparecimento duma nova ontologia da subjetividade. Colocando-nos na estrada que foi do Foucault, e do Foucault estudioso das práticas de vida, e do ascetismo, podemos dizer que uma nova metódica do diálogo da consciência consigo mesma, comparáveis com as de Santo Agostinho e com as que Descartes fixara no século XVII, põe-se em frente à observação de Nietzsche. $O$ pensamento da subjetividade de Nietzsche, sobretudo

\footnotetext{
* Pós-doutorando no Instituto de Filosofia da Linguagem da FCSH da Universidade Nova de Lisboa, Portugal, e colaborador nas Universidades de Pisa e della Calabria, Itália, no âmbito do Centro “Colli-Montinari”. Endereço eletrônico: gianfranco.ferraro@gmail.com
}

Cad. Nietzsche, Guarulhos/Porto Seguro, v.36 n.2, p. 165-176, 2015. | 165 
Ferraro, G.

onde tem mais relevância para o gênero biográfico, é portanto uma etapa decisiva na história do gênero literário da "confissão". Ao mesmo tempo, esse tem uma relevância extraordinaria para a história da "confissão" como "prática" da escrita. A forma da subjetividade própria da modernidade cartesiana é nomeadamente atravessada nesta altura por um dispositivo de interrogação finalizado a destitui-la. Um dispositivo de interrogação que questiona como o sujeito relaciona-se consigo mesmo: temos que fazer portanto uma "arqueologia" que pretenda atravessar as formas da escrita do "si", não procurando delas uma origem histórica, uma fonte primaria pela qual no occidente o sujeito ter-se-ia descoberto o outro do "si", mas sim alguns pontos de fratura dessa tensão subterrânea que anima essa relação. É oportuno neste sentido referirmo-nos ao que Michel Foucault escreve na sua "Arqueologia do Saber":

A constituição de uma obra completa ou de um opus presupõe um determinado número de escolhas que não é fácil justificar nem muito menos formular: é suficiente acrescentar aos textos publicados pelo autor os que ele tinha o projeto de editar, e que ficaram incompletos, pela simples razão que ele morreu? É necessário integrar também tudo o que é esboço, primeiro esquisso, correcções e riscos dos livros? É preciso acrescentar os esboços abandonados? E qual estatuto podemos dar às cartas, às notas, às conversações referidas, aos propósitos transcritos para os ouvintes, em suma, ao imenso formigar de rastos verbais que um indivíduo deixa em seu redor no momento em que morre, e que falam no interior de um cruzamento indefinido, liguagens tão distintas? [...] De fato, se falarmos tão de boa vontade, e sem nos interrogar em demasia da "obra" de um autor, é porque a supomos definida por uma determinada função expressiva. ${ }^{1}$

Para o Foucault autor da Arqueologia, interrogar os discursos

1 FOUCAULT, Michel. L'archéologie du savoir. Paris: Gallimard, 1969, p. 35.

166 Cad. Nietzsche, Guarulhos/Porto Seguro, v.36 n.2, p. 165-176, 2015. 
e as escritas, nas suas relações com o autor, significa precisamente percorrer a tensão pela qual são atravessados: os discursos não são lugares tranquilos, não tem uma forma definitiva. O que é importante fazer é interrogar - e vemos aqui uma das maiores heranças do pensamento metodologico de Nietzsche - as periferias dos eventos que originaram as escolhas discursivas. Examinando os discursos confissionais, as meditações, as biografias, até onde esses parecem contaminadas pela fictio, chegamos a compreender como o próprio método arqueológico de Foucault possa ser aplicado, na senda do que o autor logo traçou no seu curso sobre a Hermenêutica do Sujeito (1982-1983), as práticas da escrita em que o próprio "si" é questionado. Mas quais são os instrumentos de um metodo arqueológico que se destine à investigação de algumas práticas da escrita? Se uma subjetividade exprime-se, num determinado período histórico, por uma costelação de constantes e de variantes, estilísticas e temáticas, o trabalho histórico-crítico tem de apontar para um alvo preciso: a indicação e a compreensão daquelas em que os fantasmas duma época encontram-se. É preciso, em suma, para além da mistura dos cânones filosóficos e literários que Nietzsche pratica, pôr em relevo em que termos ele decide praticar um certo gênero, como o da "confissão autobiográfica". A prática de escrita de Nietzsche pode assim colocar-se numa mais vasta história das praticas de subjetivação da modernidade, isto é, no interior de uma mais ampla história da ontologia da subjetividade moderna. Os cânones estilísticos e literários que Nietzsche pratica conscientemente, e que nos impõe de forma sistemática a meditar sobre o grau de conteúdo filosófico que existe nas figuras retóricas da inventio, próprias da literatura, e de figuralidade inventiva existente no seu pensamento, como tais são desproblematizadas e reconduzidas a um problema fundamental. De fato, considerada a escolha de utilizar uma determinada prática de escrita formalizada 
Ferraro, G.

no interior de um cânone determinado - o da Confissão - e aceitando que, na história do pensamento ocidental, é justamente esta forma a ser utilizada sempre que se quis questionar o sujeito a partir, por exemplo, de uma diferente dissecação do seu campo de acção, dos seus "eus", dos seus "tus", e das próprias referências materiais - o livro - em que a operação é levada ao cabo, o que podemos perguntar-nos é: 1) qual lugar ocupam as "confissões" de Nietzsche dentro da história literária e filosófica do gênero das confissões; 2) o gênero das confissões pode inserir-se no horizonte do que Michel Foucault chamou "práticas de cuidado de si", ou seja, essas práticas desenvolvidas na antiguidade grego-romana e helenística como epimeleia heautou, e logo transferidas ao cristianismo, entre as quais a procura filosófica da Verdade, não é senão uma prática entre as outras? Ora, Foucault não exita em convocar, em relação a esta genealogia do "si", as práticas de escrita das "vidas", assim como das "meditações" modernas sobre o si - como por exemplo as de Montaigne, Pascal, Descartes. Por isso, podemos perguntarnos, convocando por nossa vez o Ecce Homo, qual lugar Nietzsche ocupa no horizonte da história das práticas de escrita do si; 3) Uma vez colocado Nietzsche no interior desta história de longo período, não só do pensamento filosófico, e não só da história da literatura (divisão demasiado rígida que colocaria vários problemas), mas sim da longa história da "escrita do si", o problema da sua relação e da sua diferença poderá ser declinado de forma distinta: qual campo de subjetividade, e qual forma do si, ele abre e descreve? É, de fato, justamente a partir dessa perspectiva que deveríamos refletir sobre a questão do multíplice ou do teatro do si que Nietzsche especialmente a partir do último ano da sua produção - produz.

No arquétipo de todas as confissões, a de Agostinho, é importante refletir sobre como, no incipit e logo no começo no Livro décimo primeiro, o autor redefine tanto a forma Livro, em relação

168 Cad. Nietzsche, Guarulhos/Porto Seguro, v.36 n.2, p. 165-176, 2015. 
ao sujeito que escreve, como a relação entre quem escreve e o "Tu" a quem o próprio livro é oferecido, neste caso Deus. Tratase, como evidenciou o teólogo contemporâneo Jean-Luc Marion², de uma "relação a três", na qual, precisamente, algo mais do que o SI se instaura em lugar do si ("au lieu de soi") e é justamente esta transposição, este relato do si, que define os termos em que a subjetividade do autor se re-escreve, alcançado assim esse plano da transcendência sem o qual ela mesma não teria, por assim dizer, legitimação. Existe, no próprio arquétipo das confissões, a exposição de uma multidão de vozes. A confissão difere das outras escritas de vida - das vidas dos Santos, por exemplo, como dos seus derradeiros desenvolvimentos que são as biografias modernas justamente nisto: na convocação de múltiplas presenças. Escrevese, e, consequentemente, constrói-se o livro, "em presença de-". O Livro das Confissões adquire neste sentido uma estrutura vital, que pretende manter uma relação estável tanto com a vida que no Livro se desenvolve em escrita, quanto com a vida do leitor, convocado a ler. Garantia desta relação e desta estabilidade é, em Agostinho, a presença divina. É a presença divina, e a sua glorificação, a causa e o fim do movimento de confissão. É na presença divina que vivem as confissões, sem que esta presença, obviamente, tenha necessidade delas. A presença divina é neste sentido, literariamente falando, uma figura retórica precisa através da qual se constitui a escrita das confissões. Deus não precisa de confissões: é quem escreve, o sujeito que escreve, que as necessita. O "si”, portanto, confessa-se, e assim desenvolve-se: "Na nossa confissão a Ti - escreve Agostinho - das nossas misérias e das tuas misericórdias para conosco, nós desabafamos o nosso desejo que Tu, assim como começaste, também nos leve à completa libertação: cessaremos então de ser

2 Cf. MARION, Jean-Luc. Au lieu de soi. L'approche de Saint Augustin. Paris: PUF, 2008. 
Ferraro, G.

infelizes em nós e seremos felizes em Ti...". A "confissão" é para Agostinho uma prática de renovação da fé em Deus: é justamente a verdade da presença de Deus no Mundo e na vida do sujeito a ser confessada perante o mesmo Deus ("in conspectu tuo").

Ora, há uma passagem muito importante na qual Foucault indica a transformação da prática de verdade como relação com o "si": esta passagem coincide com esse século dezessete, em que se elaboram as Meditações de Descartes, também neste caso interpretadas como um certo protótipo da escrita do si. Se até então o acesso à verdade, até a verdade do si, é duplamente ligado a um exercício de ascese, com Descartes o acesso à verdade será desligado da relação com a moralidade: sabemos que para Descartes tratar-se-á de recomeçar do zero, e de libertar a consciência das impressões ilógicas, e, portanto, não verdadeiras, dos sentidos. O plano da consciência cartesiana é, antes de mais nada, fruto de uma suspensão do juízo por parte do sujeito, em relação ao que ele considerou até esse momento parte inderrogável da própria forma. A meditação, poderíamos dizer parafraseando Agostinho, acontece "in conspectu dubii". É justamente a questão que moverá, por um lado, a busca kantiana de uma ética universal e, por outro lado, a exposição que Rousseau fará da sua vida enquanto obra. Mas é na eticidade da confissão pública que Rousseau recupera Agostinho, onde a transparência da confissão equivale e legitima o ato de fé que era exigido no séc. V ("sed credunt mihi, quorum mihi aures caritas aperit") ${ }^{3}$.

Pretendo mostrar aos meus similares - escreve Rousseau - um homem em toda a verdade da sua natureza; e este homem serei eu. Eu, só. Sinto o meu coração e conheço os homens. Não sou igual a nenhum dos que encontrei; ouso acreditar que não sou como nenhum dos que existem. Embora não valha mais do que eles,

3 Aurelii Augustini, 1981, Liber X, II.

$170 \mid$ Cad. Nietzsche, Guarulhos/Porto Seguro, v.36 n.2, p. 165-176, 2015. 
pelo menos sou diferente ${ }^{4}$.

Ora, em Ecce homo, já no seu subtítulo, "como nos tornamos o que somos", Nietzsche recupera, por sua vez, na última das suas obras, justamente o gênero das Confissões. O "tu", são agora, diretamente, os leitores: "Ouçam-me! - pede Nietzsche - pois eu sou tal e tal. Sobretudo não me confundam por outra coisa!" (EH/EH, Prólogol, KSA 6.257). Mas o que é que em Ecce Homo se expõe? Lendo o texto, as várias partes constituem no fundo uma recuperação e uma re-visão dos textos em que a filosofia de Nietzsche já foi desenvolvida. A exposição consiste então, primeiramente, em deixar a nu a coincidência entre vida e obra a partir de uma tarefa comum, definida quase como num mote pelo subtítulo - "como nos tornamos o que somos", e logo pelo título do último capítulo - "porque eu sou um destino". É justamente aqui, no fim, que encontramos o núcleo da mesma pratica de escrita que governa Ecce Homo. Sarah Kofman a este propósito falou de "explosão" . O prólogo de Ecce Homo termina com a evocação do maior dom que Nietzsche pensa ter feito à humanidade: Zaratustra. O risco, avisa o filósofo, é fazer do Zaratustra um profeta: isto é, de carregar, novamente, com o peso da fé, a palavra de Zaratustra. Nietzsche, portanto, avisa o leitor, mas, por sua vez, para o fazer, coloca a máscara de Zaratustra. A confissão de verdade já se deu, e continua acontecendo, por interposta pessoa. A prática, toda ética, da verdade, necessitou, para se explicitar, de uma interposição, de um coup de théâtre: tal foi Zaratustra, tal foi Dioniso, ou o Crucificado - ou "todos os nomes da história", que serão convocados

4 ROUSSEAU, Jean-Jacques. Les Confessions. In: Oeuvres completes. Ed. par B. Gagnebin et M. Raymond. Paris: Gallimard, 1959, Livro I.

5 Cf. KOFMAN, Sarah. Explosion I. De l'Ecce homo de Nietzsche. Paris: Galilée, 1992.

Cad. Nietzsche, Guarulhos/Porto Seguro, v.36 n.2, p. 165-176, 2015. | $17 \mathbf{1}$ 
Ferraro, G.

nos "bilhetes da loucura" que daí a poucas semanas - estamos em Turim, em Dezembro de mil e oitocentos e otenta e oito - Nietzsche enviará, antes de ser reconduzido por Overbeck para a Alemanha, já demente. Máscaras necessárias, as de todas as suas obras, através as quais Nietzsche foi construindo um teatro polémico. Mas pela máscara de Zaratustra, sobretudo em Ecce Homo, Nietzsche tenta fazer as contas com o risco implícito na veneração que cada escrita do si acarreta. Risco que obviamente consiste em que, uma vez desaparecida a veneração, nos deparemos novamente, como já tinha acontecido com Wagner, com um ídolo de pedra.

Não quero 'crentes' - escreve Nietzsche - penso ser malicioso demais para acreditar em mim mesmo, nunca falo às massas... tenho um terror medonho de que um dia se me faça santo: vocês adivinharão por que me previno por tempo, com a publicação deste livro, contra todas as estupidezes que se poderiam fazer contra mim... Não quero ser santo, antes um bobo... talvez seja um bobo, e contudo, aliás, não contudo - já que nunca houve até hoje nada de mais falso do que os santos - a verdade fala em mim. Mas a minha verdade é terrível: porque até hoje chamava-se verdade à mentira $(E H / E H$, Por que sou um destino 1, KSA 6.365).

A obra de transvaloração subverte a moral cristã, mas subverte num sentido ainda mais profundo justamente os modos de produção da verdade, os modos de veridição e de legitimação do verdadeiro, que a moral e a metafísica cristã construíram. Entre estes modos achamos obviamente os modos de produção da verdade em relação a nós próprios. É justamente nesta perspectiva que uma parte da crítica nietzschiana começou a interrogar-se acerca do estatuto filosófico dos "bilhetes da loucura" escritos em Turim,

172 | Cad. Nietzsche, Guarulhos/Porto Seguro, v.36 n.2, p. 165-176, 2015. 
assinados com nomes e máscaras diferentes, a de Dioniso, a do Crucifixo, e a do próprio Nietzsche. Máscaras em que a consciência de si aparece descomposta, mas que tendem cada vez para novas direções, para interlocutores verdadeiros, verossímeis, improváveis e por vezes puramente e simplesmente impossíveis. Máscaras cujo estatuto de verdade tem que ser interrogado partindo desse mínimo comum denominador que consiste na busca de um interlocutor: a assinatura exposta, em que se representa a vida, ou uma forma inteira de vida - Dioniso - constrói-se a partir da relação com o interlocutor, da sua evocação. Neste sentido Ecce homo parece constituir, perante o público dos poucos amigos leitores e das gerações futuras, o tratamento de um si exposto à laceração, à decomposição, justamente por causa dessa prática de verdade que o investiu. Nietzsche é um decadente, mas na tarefa que ele se dá, de viver até o fim a decadência, é também a antítese do decadente. A decadência compreende também o que dela salva: “Tomei a minha mão, sozinho me curei", diz Nietzsche. Tal pode funcionar, qualquer fisiologista poderá admiti-lo, só com a condição de "ser fundamentalmente sãos". A doença, a sua exposição, é o que permite contar a história de uma cura. O filósofo terá de dar à luz esse destino, enquanto o decadente descreve, e expõe, outros, porque não se conhece. Porque a sua relação consigo mesmo é invalidada pela mentira. O Mundo, todos os seus nomes, as próprias máscaras, para Nietzsche, são relacionadas com a verdade do si: "não descrevi senão a mim mesmo", relembra Nietzsche.

Por que então não apagar tudo? Falsa é a contradição, se pensarmos ao formar-se mesmo do Livro: o fenômeno inderrogável da escrita, do deixar rastos, como autobiografia da sensação, não se coagula numa composição, mas numa descomposição de sentidos. Trata-se de notas à margem, cujo texto principal é apagado: o Livro, não tocado e intocável, é a própria vida. É para a arqueologia 
Ferraro, G.

desta vida, para a urgência que um "si” futuro terá desta arqueologia, que essas notas remetem. Cuidado, portanto, ao tomarmos a sério o livro, fazendo dele filologia. O fenómeno literário que nos é legado, é sim duro como a pedra, e sempre o será ao lê-lo, mas do momento em que exige de ser o resto de uma vida, e não apenas uma sua reinvenção, o trabalho do leitor não é apenas o da filologia, mas também o da arqueologia. Temos que olhar, no seu complexo, para a prática da escrita: a imputação do fenómeno que temos à frente é complexa, como pode ser complexa a definição da matéria para as ciências exatas dos anos 20 do séc. XX. A partir do momento em que uma grande parte dessa definição deve confrontar-se com quanta de energia que aludem a uma presença outra, preponderante, que se pode intuir apenas partindo dos rastos que ficam. A antimatéria está à vida como a matéria está ao livro. Ou, para utilizar a metáfora psicanalítica, no texto da confissão, sobretudo onde vemos uma mistura com a ficção, é localizável o que está em jogo no lapsus ou no witz: trata-se de um rasto de verdade 6 . O lugar primigênio é disperso, a escrita do "si" é portanto o que retém a angústia esquizóide do estar no mundo.

Mesmo na distância, Nietzsche parece habitar um mesmo lugar, uma mesma topografia da alma, contraposta ou complementar em relação ao que Freud descobria em anos intermédios à obra daquele. As lógicas inconscientes que decompõem a subjetividade, no fim do século XIX, são as mesmas que fazem soçobrar a forma da subjetividade e que, então, questionam a forma da relação do indivíduo consigo mesmo e com os outros. O risco trágico da loucura é feito desta travessia. Reconhecer a multiplicidade dos planos em que a consciência se estrutura exige que os reabitemos, que os re-frequentemos e, portanto, que os reproduzamos. A recuperação do gênero das confissões por Nietzsche comporta a

6 Cf. ORLANDO, Francesco. Saggio introduttivo a S. Freud, Il motto di spirito. Torino: Bollati Boringhieri, 1975, pp. 15-29.

174 | Cad. Nietzsche, Guarulhos/Porto Seguro, v.36 n.2, p. 165-176, 2015. 
re-proposição e a deslocação do conceito do si. O livro é exposto ao falhanço: como uma cura de si, enquanto prática extrema sobre um si já não regulado conforme as leis que o disciplinavam, o qual pode atingir o estatuto de uma prática paralela de revisão.

Reconhecer a multiplicidade dos planos em que se estrutura a consciência significa habitá-los, frequentá-los, e, portanto, produzi-los. Como um cuidado do "si", que, como prática extrema sobre um "si" já não regulado conforme leis de uma subjetividade vinculada à história, é para sempre exposto não a um falhanço, mas a uma diferente necessidade de leitura. Nesta perspectiva, a fictio confissional de Ecce homo preludia a abertura de uma topografia da alma que já não se pode reconduzir ao confronto eu-eu. A confissão entra num espaço aberto, em que ao discurso produzido pela dualidade se vem a substituir um momento de confronto em que a voz é balbúcie efêmera do que atormenta um espaço interior que, mantendo-se inerente à expressão, põe continuamente em xeque as suas posibilidades. Nietzsche acaba afundando a própria expressão no nada que a habita, resistindo apenas, um momento antes, como pluralidade de nomes. A heteronimia, assim como a construção de um possível Livro de confissões, apresentam-se, portanto, como estratégias de mediação perante a emergência do impossível, um impossível que escava para além das regras permitidas pelo gênero das confissões e pela prática do "si" que esse gênero regula.

\begin{abstract}
At the end of XIX century, the experience of modern subjectivity lives on a shift of questions that go through and manifest themselves in unusual forms of writing. In the recovery of the autobiographical gender, the Nietzsche of Ecce homo is quite aware that just a new form of a dialogue of self-consciousness can set the image of this new "I", just as happened with Augustine's Confessions and Descartes' Meditations.
\end{abstract}

Keywords: Ecce homo - confession - Foucault - form of life

Cad. Nietzsche, Guarulhos/Porto Seguro, v.36 n.2, p. 165-176, 2015. | 175 
Ferraro, G.

\section{referências bibliográficas}

AURELII AUGUSTINI, SANCTI. "Confessionum libri tredecim". In: Opera omnia. Editio latina. Roma: Città Nuova, 1981.

FOUCAULT, Michel. L'archéologie du savoir. Paris: Gallimard, 1969.

FOUCAULT, Michel. L'Herméneutique du sujet. Cours au Collège de France 1981-1982. Paris: Gallimard, 2001.

MARION, Jean-Luc. Au lieu de soi. L'approche de Saint Augustin. Paris: PUF, 2008.

ORLANDO, Francesco. Saggio introduttivo a S. Freud, Il motto di spirito. Torino: Bollati Boringhieri, 1975.

KOFMAN, Sarah. Explosion I. De l'Ecce homo de Nietzsche. Paris: Galilée, 1992.

NIETZSCHE, F. Sämtliche Werke. Kritische Studienausgabe (KSA), edição a cargo de Giorgio Colli e Mazzino Montinari. Berlin/München: dtv/de Gruyter, 1980.

ROUSSEAU, Jean-Jacques. Les Confessions. In: Oeuvres completes. Ed. par B. Gagnebin et M. Raymond. Paris: Gallimard, 1959.

Artigo recebido para publicação em 31/03/2015.

Artigo aceito para publicação em 31/08/2015.

176 Cad. Nietzsche, Guarulhos/Porto Seguro, v.36 n.2, p. 165-176, 2015. 